\title{
A CLOSER LOOK AT THE ABI ON THE GOES-R SERIES
}

\author{
Timothy J. Schmit, Paul Griffith, Mathew M. Gunshor, Jaime M. Daniels, \\ SteVen J. Goodman, and William J. Lebair
}

\begin{abstract}
The $A B I$ on the GOES-R series is America's next-generation geostationary advanced imager and will dramatically improve the monitoring of many phenomena at improved time and space scales.
\end{abstract}

T he era of imaging the Earth from the geostationary perspective began on 6 December 1966 with the launch of an experimental sensor (Spin-Scan Cloudcover Camera) on board Application Technology Satellite-1 (ATS-1; Suomi and Parent 1968). The first operational follow-on satellite was the Geostationary Operational Environmental Satellite-1

AFFILIATIONS: SCHMIT-NOAA/NESDIS/Center for Satellite Applications and Research/Advanced Satellite Products Branch, Madison, Wisconsin; GRIFFITH-Space and Intelligence Systems, Harris Corporation, Fort Wayne, Indiana; GUNSHOR-Cooperative Institute for Meteorological Satellite Studies, University of Wisconsin-Madison, Madison, Wisconsin; DANIELS-NOAA/ NESDIS/Center for Satellite Applications and Research, Operational Products Development Branch, College Park, Maryland; GOODMAN-NOAA/NESDIS/GOES-R Program Office, Greenbelt, Maryland; LebAIR - NASA Goddard Space Flight Center, Greenbelt, Maryland CORRESPONDING AUTHOR E-MAIL: Timothy J. Schmit, tim.j.schmit@noaa.gov

The abstract for this article can be found in this issue, following the table of contents.

DOI:10.II75/BAMS-D-15-00230.I

A supplement to this article is available online (10.II75/BAMS-D-I5-00230.2)

In final form 27 May 2016

(02017 American Meteorological Society
(GOES-1), launched in October 1975 (Davis 2007). ATS-1 had only visible sensors, while GOES-1 had both visible and infrared (IR) sensors, allowing for monitoring clouds at night. Subsequent generations of sensors improved the spectral coverage, added an operational sounder, and many other improvements (Menzel and Purdom 1994). The Advanced Baseline Imager (ABI) on the GOES-R series continues this coverage, with a greatly improved sensor. The mission of the $\mathrm{ABI}$ is to measure Earth's radiant and reflective solar energy at moderate spatial and spectral resolution and high temporal and radiometric resolution. The first satellite in the GOES-R series was launched on 19 November 2016. The ABI is a state-of-the-art 16 -band radiometer, with spectral bands covering the visible, near-infrared, and IR portions of the electromagnetic spectrum (Table 1). Many attributes of the ABI-such as spectral, spatial, and temporal resolution; radiometrics; and image navigation/ registration-are much improved from the current series of GOES imagers. This paper highlights and discusses the expected improvements of each of these attributes. Many higher-level-derived products can be generated from ABI data and used in a large number of environmental applications. The ABI's design allows for rapid scan and contiguous U.S. imaging automatically interleaved with full disk (FD) scanning. The information from the ABI on the GOES-R 
TABLE I. ABI FMI spectral attributes [band number, center wavelength, $50 \%$ full width at half maximum (FWHM) minimum-FWHM maximum, approximate subpoint ground sampling distance, and name].

\begin{tabular}{|llllll|}
\hline ABI band & $\begin{array}{l}\text { Approx central } \\
\text { wavelength }(\boldsymbol{\mu m})\end{array}$ & $\begin{array}{l}\text { FWHM at 50\% } \\
\text { minimum }(\boldsymbol{\mu m})\end{array}$ & $\begin{array}{l}\text { FWHM at 50\% } \\
\text { maximum }(\boldsymbol{\mu m})\end{array}$ & $\begin{array}{l}\text { Subpoint pixel } \\
\text { spacing }\end{array}$ & Descriptive name \\
\hline 1 & 0.47 & 0.45 & 0.49 & 1 & Blue \\
\hline 2 & 0.64 & 0.60 & 0.68 & 0.5 & Red \\
\hline 3 & 0.864 & 0.847 & 0.882 & 1 & Vegetation \\
\hline 4 & 1.373 & 1.366 & 1.380 & 2 & Cirrus \\
\hline 5 & 1.61 & 1.59 & 1.63 & 1 & Snow/ice \\
\hline 6 & 2.24 & 2.22 & 2.27 & 2 & Cloud particle size \\
\hline 7 & 3.90 & 3.80 & 3.99 & 2 & Shortwave window \\
\hline 8 & 6.19 & 5.79 & 6.59 & 2 & $\begin{array}{l}\text { Upper-level water } \\
\text { vapor }\end{array}$ \\
\hline 9 & 6.93 & 6.72 & 7.14 & 2 & Midlevel water vapor \\
\hline 10 & 7.34 & 7.24 & 7.43 & 2 & Lower/midlevel water \\
vapor
\end{tabular}

series will be used for many applications related to severe weather, tropical cyclones and hurricanes, aviation, natural hazards, land and ocean surfaces, and the cryosphere. The calibrated, geolocated ABI information will be used to produce a wide variety of weather and environmental data products and to monitor rapidly changing weather (Lindsey et al. 2012). The GOES-R series provides a set of six scientific instruments in the geostationary orbit on four identical spacecraft. While the spacecraft will launch in sequence, once on-orbit they will be deployed so that there is an operational satellite at both the operational east and west positions, with an on-orbit spare. Also of note is that prior to launch, satellites are referred to by letters, which are changed to numbers once they have been placed in the geostationary orbit. Thus, GOES-R was renamed GOES-16 on 29 November 2016. The primary Earth-viewing instrument is the ABI. The GOES-R series also will carry the first Geostationary Lightning Mapper (GLM) to monitor total lightning activity with a nearly uniform storm-scale spatial resolution of $8 \mathrm{~km}$ across most of the Western Hemisphere (Christian et al. 1989; Goodman et al. 2013). Among many other uses, the GLM will complement the ABI information for nowcasting and short-term forecasting of rapidly developing high-impact and severe convective weather in regions of overlapping coverage (Goodman et al. 2012; Stano et al. 2014; Gravelle et al. 2016), as well as extend the lightning and thunderstorm climatology of the Western Hemisphere initially established by the Tropical Rainfall Measuring Mission (Cecil et al. 2014; Albrecht et al. 2016). GOES-R will also monitor the sun and the solar environment (Kalluri et al. 2015b). The instruments to be used include the Solar Ultraviolet Imager (SUVI), the Extreme Ultraviolet Sensor/X-Ray Sensor Irradiance Sensors (EXIS), the Space Environment In-Situ Suite (SEISS), and the Magnetometer.

Data from Japan's next-generation imager, the Advanced Himawari Imager (AHI), are being used by the National Oceanic and Atmospheric Administration (NOAA) to prepare for the ABI. The AHI is very similar to the ABI and was launched on 7 October 2014. AHI became operational on 7 July 2015 (Da 2015; Okuyama et al. 2015; Bessho et al. 2016). Like the ABI, the AHI instrument was built by Harris Corporation and has 15 of its 16 spectral bands similar to ABI, the major difference being that AHI has a $0.51-\mu \mathrm{m}$ (green) spectral band instead of the ABI $1.37-\mu \mathrm{m}$ (cirrus) band. The main use for the $0.51-\mu \mathrm{m}$ band is the generation of true color imagery, which is further improved by using the $0.86-\mu \mathrm{m}$ band (Miller et al. 2016). For the ABI, the green band will need to 
be simulated (Miller et al. 2012) in order to effectively generate true color imagery.

There have been several changes to the GOES-R series since the earlier description in Schmit et al. (2005). Most significantly, the spacecraft will not include an advanced infrared sounder or a coastal waters sensor (Hayden and Schmit 1991; Schmit et al. 2009a). This sensor had been called the Advanced Baseline Sounder, and then the Hyperspectral Environmental Suite (HES). There will be no sounder at all on the GOES-R series, and hence any legacy products from the current-generation GOES sounder, such as the lifted index, will need to be generated from the ABI (Schmit et al. 2002, 2008); however, the quality of these temperature and moisture profiles and derived parameters will be much less than they would have been from an advanced high-spectralresolution sounder.

In preparation for the rapid scan imagery from the ABI, the GOES-14 imager provided near-real-time 1-min imagery to forecasters as part of a Super Rapid Scan Operations for GOES$\mathrm{R}$ (SRSOR) experiment for several periods in 2012-16 (Schmit et al. 2013, 2015). GOES-14 was able to be used in this manner, since it is the on-orbit backup GOES. During SRSOR, 1-min imagery is obtained for 26 contiguous times in the span of $30 \mathrm{~min}$, with a brief interruption for calibration. Many uses of these SRSOR data have been demonstrated, both in the research and operational environments (Bedka et al. 2010; Dworak et al. 2012; Bedka et al. 2015; Mecikalski et al. 2016; Line et al. 2016; Apke et al. 2016;). The first known use of 1-min satellite data
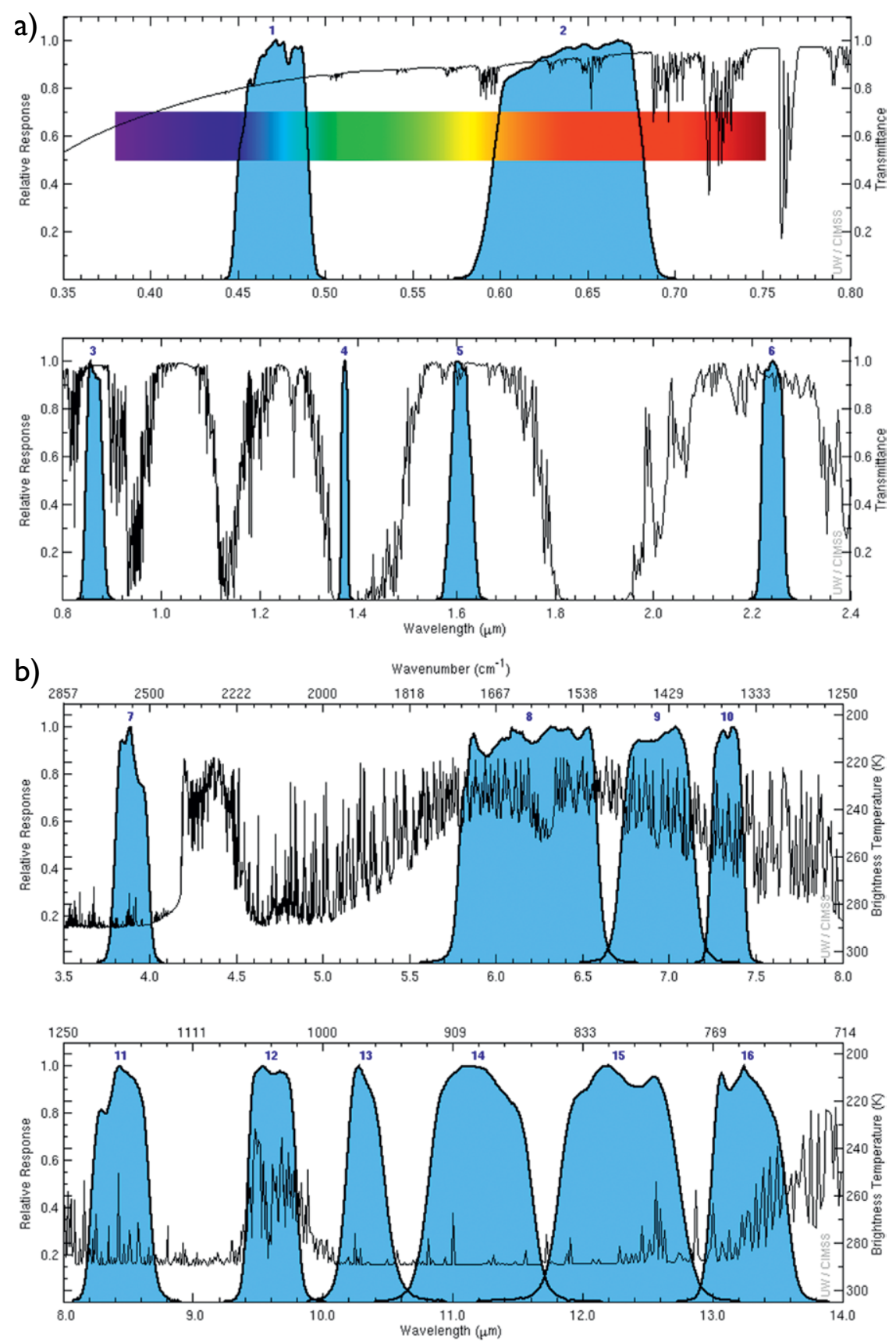

FIG. I. ABI FM I spectral response plot of the visible and (a) near-IR bands and (b) IR bands; (a) also has a high-spectral-resolution atmospheric transmittance plot, while (b) has high-spectral-resolution IR Earth-emitted spectra. Note that in (b), the temperature decreases as the ordinate increases. 


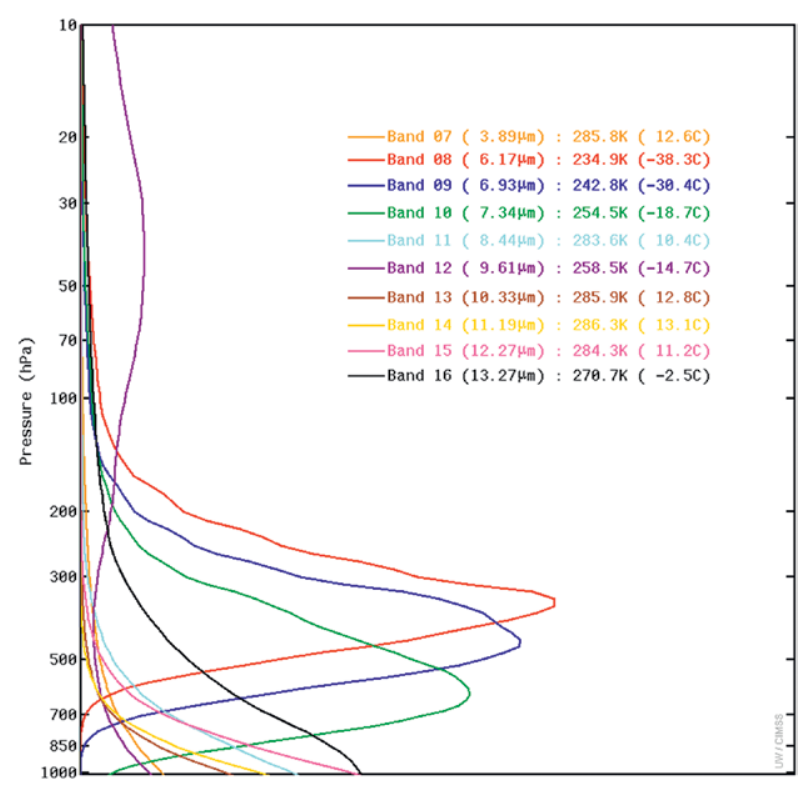

FIG. 2. ABI IR vertical weighting (or contribution) functions for the U.S. Standard Atmosphere, 1976 (COESA 1976). Note that the calculated clear-sky brightness temperature is also plotted. These plots represent the nadir view.

ongoing activities being done within the GOES-R Algorithm Working Group (AWG), the Calibration Working Group, the Product Working Group, the GOES-R Risk Reduction Program, the GOES-R Proving Ground Program, and the Education Proving Ground Program. All groups contribute to the goal of preparing NOAA and its users for the data and products that will come from GOES-R (Daniels et al. 2008; Goodman et al. 2012; Ralph et al. 2013; Gravelle et al. 2016; Greenwald et al. 2016).

The GOES-R series offers the critical continuity of geostationary imager observations over the Americas and a large portion of the Pacific Ocean until the mid2030s. The following sections cover the ABI instrument and its attributes, ABI scan scenarios, derived (Level 2) products, and data distribution. Working in conjunction with the ABI, the GLM will provide complementary diagnostic information on rapidly developing and intensifying storms. The GLM total lightning detection, a Level 2 product, contains information on the time, location, radiance, initiation, and horizontal extent of each lightning flash. Prior studies have shown the temporal trends of the total lightning flash rate and its extent are useful descriptors of the storm intensity and offer the potential to increase forecaster confidence and increase warning lead time (Schultz et al. 2009; Gatlin and Goodman 2010; Schultz et al. 2013; Stano et al. 2014; Bruning and MacGorman 2013). GOES-R Proving Ground imagery and lightning product demonstrations at the NOAA Aviation Weather Center, Weather Prediction Center, Ocean Prediction Center, and the National Hurricane Center suggest the combination of ABI and GLM offer the potential to better characterize the strength of convective hazards and the potential impacts over the oceans and other data-sparse regions in the absence of radar (Zipser and Lutz 1994; Petersen et al. 2005; Zipser et al. 2006; Goodman et al. 2012).

INSTRUMENT OVERVIEW. The development of the $\mathrm{ABI}$ is being done as a collaborative effort between the National Aeronautics and Space Administration (NASA) and NOAA. Designed and built by Harris Corporation (formerly Exelis, which was formerly ITT Geospatial Systems), it will fly on the GOES-R series of geostationary satellites. The ABI is a 16-channel (Fig. 1) imaging radiometer that provides significantly increased capabilities over the current operational GOES imager by way of more spectral channels, higher spatial resolutions, interleaved image collections, and faster image repetition rates. The ABI has 11 more channels than the current GOES imager. Similar to the current GOES imager, the material used for the ABI detectors vary by spectral band, with silicon (Si) being used for the visible (wavelength less than $1 \mu \mathrm{m}$ ) and mercury cadmium telluride ( $\mathrm{HgCdTe}$ ) for the nearIR and IR bands (wavelength greater than $1 \mu \mathrm{m}$ ). The

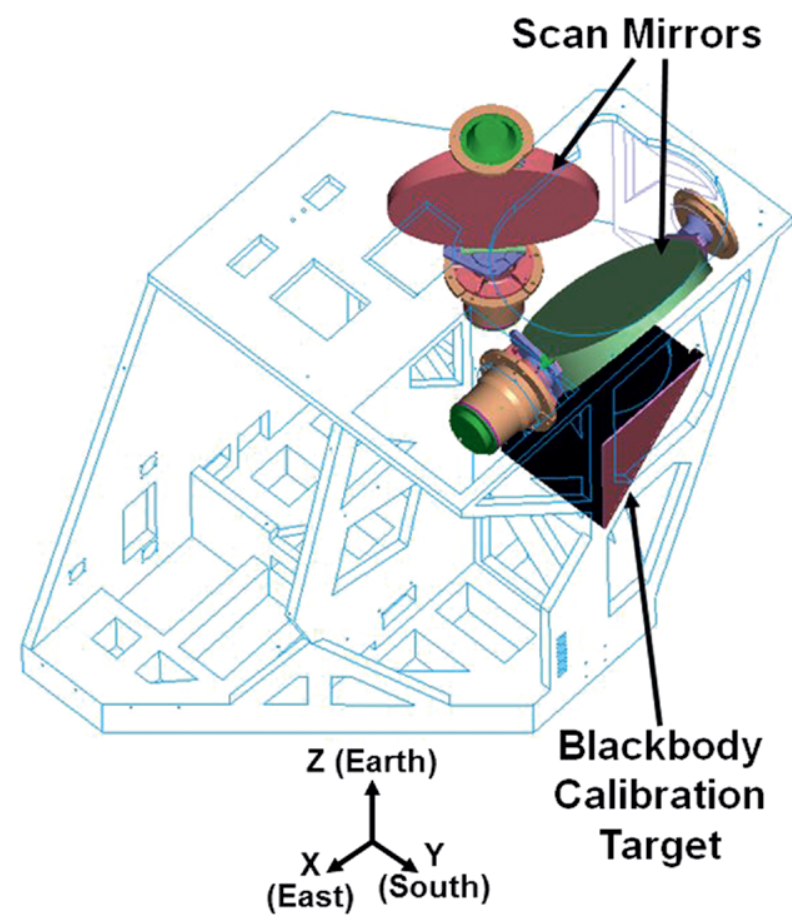

FIG. 3. Schematic of the $A B I$ sensor unit. The nature of the two-mirror scanner is shown. The Earth-facing optical port is "up" (or the $z$ direction) in this figure. 
corresponding vertical weighting (or "contribution") function for the IR bands, denoting the sensitivity of each channel to different layers in the atmosphere, is shown in Fig. 2. The ABI coverage rate improves by a factor of 5 over that of the current GOES imager, and the spatial resolution improves by a factor of 4 (e.g., a factor of 2 in each pixel direction) (Schmit et al. 2005). For calibration, the ABI will have an onboard solar diffuser, similar to the NASA Moderate Resolution Imaging Spectroradiometer (MODIS; (Xiong et al. 2005), which the current GOES instruments do not have. This onboard device will greatly improve the radiometric quality of the visible and near-IR bands. ABI will also have an improved blackbody target for calibration of the IR bands. The number of bits per pixel (radiometric resolution) is also improved on the ABI (12 for most bands; 14 for the 3.9- $\mu \mathrm{m}$ band) compared to 10 bits per pixel for the current-generation GOES imager. It should be noted that the maximum saturation temperature for the $3.9-\mu \mathrm{m}$ band is also greatly improved, to greater than $400 \mathrm{~K}$. The saturation temperature for this band on the current GOES imager varies but is only about $337 \mathrm{~K}$.

The ABI instrument consists of three units: the sensor unit (SU), the electronics unit (EU), and cryocooler control electronics (CCE). The SU is shown in Fig. 3. All electronics are fully redundant, as are the detector arrays, meaning there are built-in spare components should they be needed. The ABI uses an orthogonal two-mirror scanner. To get the scale of the ABI and GOES-R series spacecraft, the long direction of the ABI instrument is approximately $1.75 \mathrm{~m}$, while the spacecraft bus is about $5 \mathrm{~m}$, and the deployed solar array is over $11 \mathrm{~m}$ from the center of the spacecraft bus. More information about the current GOES instruments can be found in the "NASA GOES-N Databook" (Boeing 2006).

The nadir spatial resolution of the ABI channels is $0.5 \mathrm{~km}$ (ABI band 2), $1 \mathrm{~km}$ (ABI bands 1,3 , and 5), and $2 \mathrm{~km}$ (the remaining bands, including all the infrared bands). The ABI pixels are spaced at constant angles $(14,28$, and $56 \mu \mathrm{rad})$. These pixels are calculated from the surrounding downlinked detector samples. Resolution is defined by the modulation transfer function (MTF) requirements, which are one of three spatial response requirements that ensure the ABI images are sharp and the data products are free from spatial response artifacts. The other two requirements are for ringing, which limits the overshoot and undershoot at sharp edges in the image,

TABLE 2. ABI FMI average SNR (or NEdT), for comparison; current GOES imager values are also included. Spec refers to the specified values and measured refers to on-orbit values. The units for the reflective bands are SNR at $100 \%$ albedo, while the units for the emissive bands are NEdT (K). Note that ideally one wants a larger SNR but a smaller NEdT.

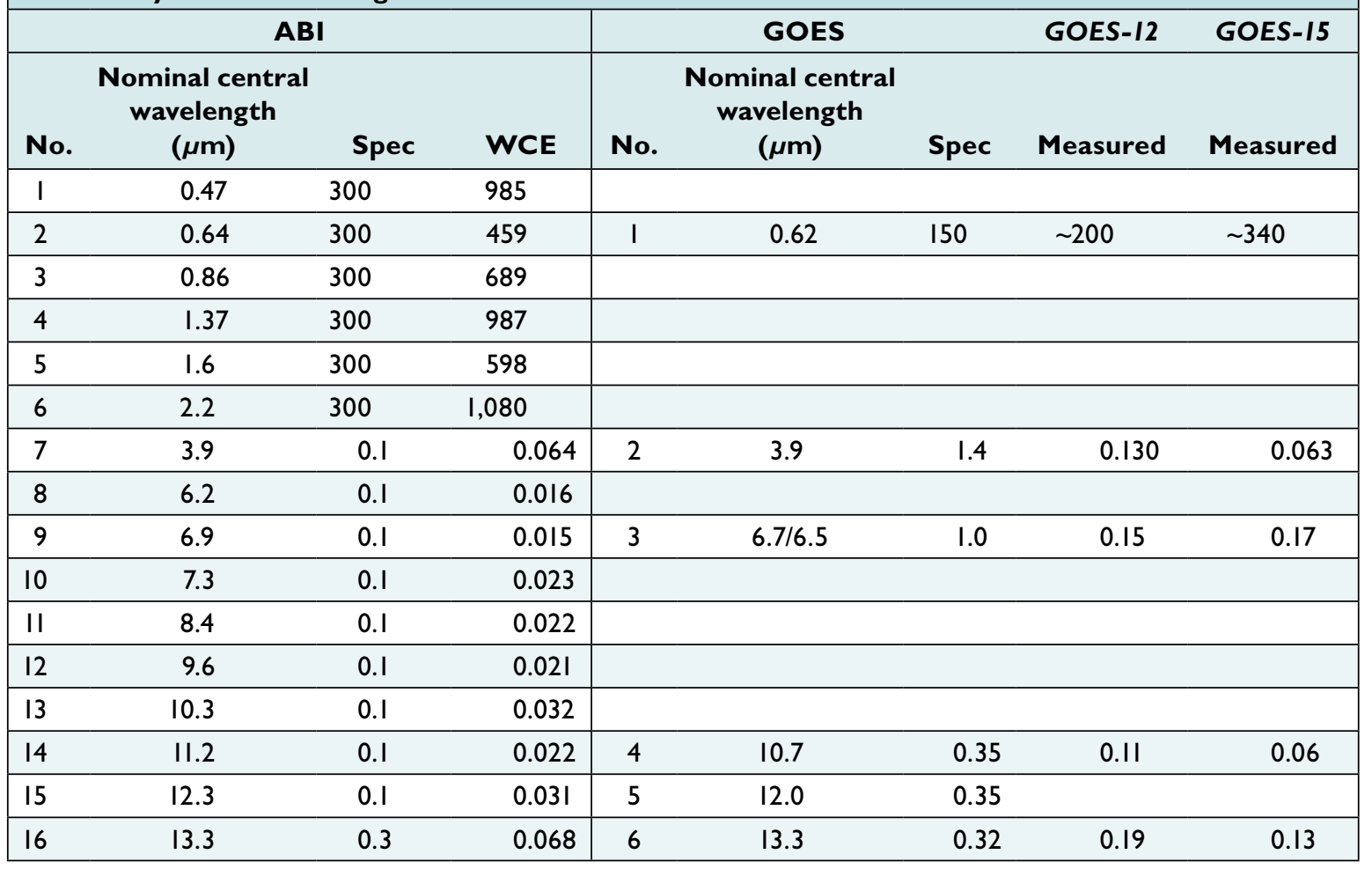




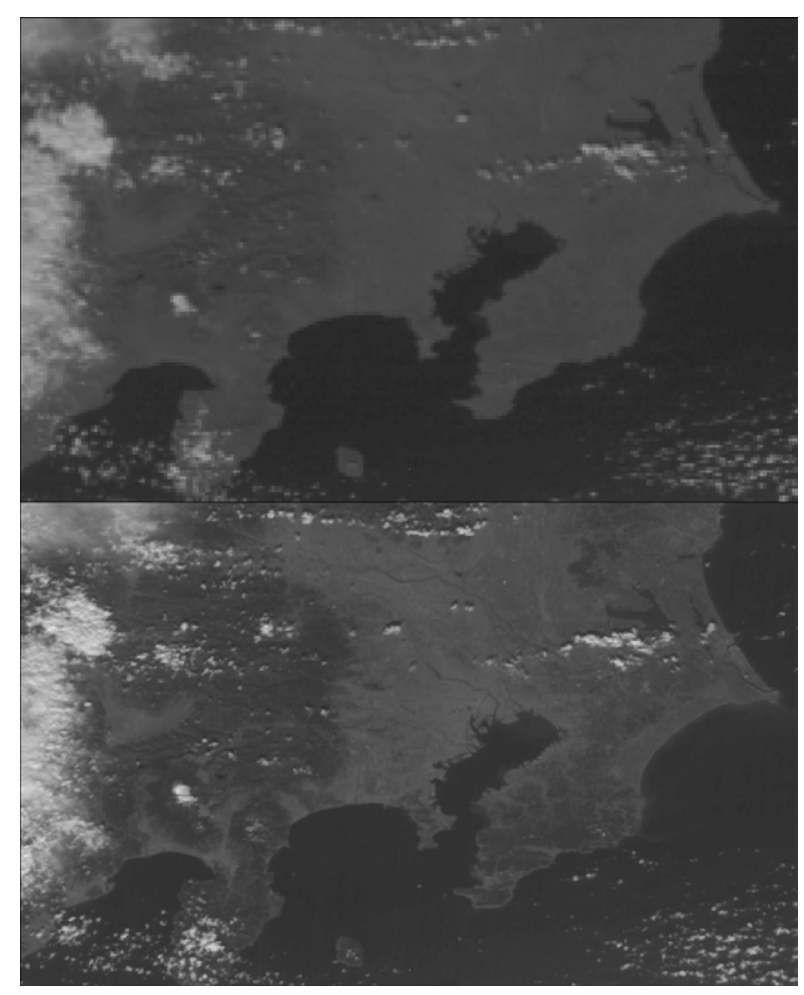

FIG. 4. The improved spatial resolution from an $A B I$ is demonstrated with data from (bottom) Japan's AHI compared to (top) the Multifunctional Transport Satellite (MTSAT). Visible band (band 3, or $0.64 \mu \mathrm{m}$, for the $\mathrm{AHI}$ ) data for $4 \mathrm{Dec} 2015$, showing the region near Tokyo, Japan. The start times are 0230 and 0232 UTC, respectively. The albedo range used was from $0 \%$ to $\mathbf{9 0 \%}$, employing a square-root enhancement.

and spatial response uniformity, which ensures that multichannel data products do not contain artifacts due to differences in the spatial response of the channels utilized. More information regarding requirements can be found on the GOES-R page ( $w$ ww .goes-r.gov/resources/docs.html), for example, the Level I Requirements Document (LIRD), the Mission Requirements Document (MRD), and the Ground Segment Project Functional and Performance Specification (FPS).

The ABI instrument design and the ABI resampler were optimized as a complete system so the final images meet these spatial response requirements. The purpose of the resampler is to remap from a number of detector samples to a uniform set of pixels. This step allows for more accurate frame-to-frame products. The accuracy of the imagery and derived Level 2 products is driven by the signal-to-noise ratio (SNR) of the data from which they are produced. For reflective channels this is measured by the SNR. For emissive channels, the noise-equivalent differential temperature (NEdT) is used. In prelaunch testing, ABI scored very well against this metric. As can be seen in Table 2, there is significant margin against the SNR (e.g., almost 1,000:1 for band 1, while the specification is only 300:1) and against most NEdT requirements, sometimes by more than a factor of 2 or 3 or more. The reference temperature for NEdT is $300 \mathrm{~K}$. Even under worst-case assumptions, the 3.9$\mu \mathrm{m}$ channel meets the NEdT requirement (Table 2). Note that ideally one wants a larger SNR but a smaller NEdT. While Table 2 is for ABI flight model 1 (FM1), which flew on GOES-R (GOES-16), similar values are expected for the follow-on ABIs. The worst-case estimate (WCE) refers to an end-of-life estimate and has similar instrument noise to the current GOES imager, even with 4-16 times finer spatial resolutions. NEdT is specified for ABI at $300 \mathrm{~K}$ for all bands, but the NEdT for the water vapor bands is specified at $230 \mathrm{~K}$ for the GOES imager (Baucom et al. 1999; Hillger et al. 2003; Hillger and Schmit 2011).

Figure 4 shows the improved spatial resolution-in this case for a visible band on the AHI, an instrument very similar to the ABI. See Fig. 6 in Schmit et al. (2005) for a similar figure showing the improved spatial resolution for the longwave infrared window, between GOES and MODIS reduced to ABI spatial resolutions. The system-level ABI navigation specification for the IR bands is to be less than $28 \mu \mathrm{rad}(3 \sigma)$; WCE has been estimated to be approximately a factor of 2 improved. For the geostationary altitude, $28 \mu \mathrm{rad}$ equates to $1 \mathrm{~km}$ at nadir. The ABI navigation performance is to be compared with $86 \mu \mathrm{rad}$ specified for the GOES-13, -14 , and -15 series imagers under normal conditions, which is relaxed to $106 \mu \mathrm{rad}$ during satellite eclipse periods (around satellite midnight). The specifications for the earlier GOES-8 series were 112 and $168 \mu \mathrm{rad}$ for the same two periods, respectively. In summary, the image navigation and registration (INR) performance will be greatly improved for $\mathrm{ABI}$ over the current GOES series. Also improved will be the shorter data outages on the ABI compared to current GOES. 


\section{SELECT APPLICATIONS OF GOES-R SERIES BASELINE PRODUCTS}

\section{Weather forecasting:}

- Cloud and moisture imagery (key performance parameter for GOES-R series)

- Cloud products (situational awareness, aviation safety, aircraft icing, surface transportation)

- Derived motion winds (situational awareness)

- Hurricane intensity (situational awareness, tropical cyclone forecasting)

- Land surface temperature (frost/ freeze warnings)

- Fire (weather and air quality forecasting)

NWP:

- Level Ib radiances (assimilation into mesoscale, regional, and global NWP data assimilation systems; model verifications)

- Derived motion winds (assimilation into mesoscale and global NWP data assimilation systems)

\section{Environmental monitoring:}

- Volcanic ash (aviation safety, health safety)

- Cloud products (climate studies, especially the diurnal cycles)

- Land surface temperature (climate studies, fire potential)
- Temperature/moisture soundings (nowcasting, convective potential and morphology, situational awareness in preconvective environments for potential watch/warning scenarios)

- Total precipitable water [nowcasting, Gulf of Mexico return flow, southwest U.S. monsoon, quantitative precipitation forecast (heavy rain, flash flooding), convective potential and morphology, fog potential, situational awareness in preconvective environments for potential watch/ warning scenarios]

- Cloud products (cloud initialization, verification of model-derived clouds, model verifications)

- Land surface temperature (assimilation into land surface models, model verifications)

- Hotspot detection and characterization (aerosol and air quality forecasting)

- Fire/hotspot characterization (air quality forecasting, life and property)

- Downward shortwave radiation (surface) and reflected shortwave radiation (TOA): climate studies, assimilation into and independent verification for surface (land and
- Atmospheric stability indices (convective potential and morphology, situational awareness in preconvective environments for potential watch/ warning scenarios)

- Rainfall rate (nowcasting, flash flood forecasting)

- Snow cover (hydrologic forecasts and warnings, including river and flood forecasts)

- Smoke and dust detection (air quality forecasting, air quality assessment and management)

- Sea surface temperature (assimilation into NWP data assimilation systems)

- Rainfall rate (assimilation into hydrologic models, model verifications)

- Snow cover (assimilation into and verification of snow models)

ocean) energy budget models, crop modeling, fire risk assessment, Earth energy budget studies

- Snow cover (streamflow forecasting/modeling, snowpack monitoring, analysis, water management, climate studies)
See the online supplemental material (http:// dx.doi.org/I0.II75/ BAMS-D-I5-00230.2) for animations from the GOES-14 imager during SRSOR mode that demonstrate the vast improvements in temporal resolution that $\mathrm{ABI}$ will bring. Both of the examples in the supplemental material [Fig. ES1 (IR) and Fig. ES2 (visible)] are from 23 May 2015 and demonstrate 1-min imagery, compared to the routine cadence of imagery from the current GOES imager (15 min). This type of rapid refresh imagery will be available with $\mathrm{ABI}$ at two separate locations, in what will be called a mesoscale scan, and at higher spatial resolution than the GOES-14 imager example shown here. More about ABI's scan modes will be discussed in the next section. With regard to similar animations, NOAA's Storm Prediction Center mesoscale discussion (SPC MD) made note of both the IR and visible SRSOR data:

THIS EWD [eastward]-PROPAGATING BOWING STRUCTURE SHOULD WEAKEN IN THE PROGRESSIVELY MORE STABLE AIR MASS LIKELY
PRESENT OVER THE E-CNTRL [central] TX PANHANDLE. 1-MIN IR IMAGERY SUGGESTS THIS MAY ALREADY BE UNDERWAY AS THE AREAL EXTENT OF COLDEST CLOUD TOPS HAS BEGUN TO DECREASE IN THE PAST HALF HOUR. (NOAA 2015a)

\section{1-MINUTE VISIBLE IMAGERY REVEALS GRAD- UALLY DEEPENING CUMULUS AS HEATING OCCURS WITHIN A VERY MOIST AIR MASS WITH SFC [surface] DEW POINTS IN THE MID- UPPER 60S. (NOAA 2015b)}

More information on how the SPC uses 1-min imagery operationally can be found in Line et al. (2016).

ABI SCAN SCENARIOS. The ABI actually scans slower than the current imager, but because it has many more detectors, the ABI covers the Earth much faster. The improved coverage rate and improved spatial resolution of the $\mathrm{ABI}$ is possible due to the 

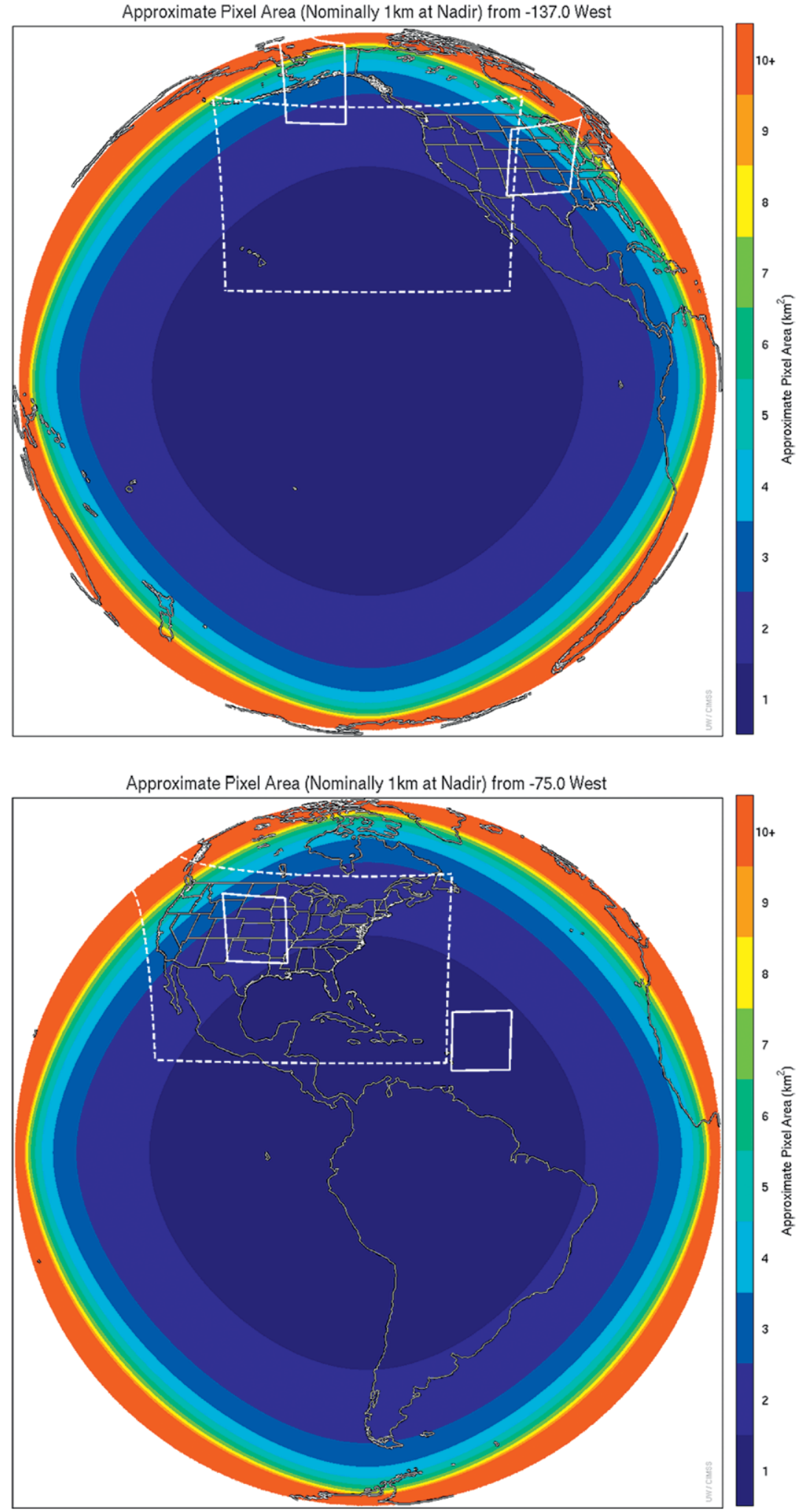

FIG. 5. ABI coverage in scan mode 3 (or flex mode) from the (top) west $\left(137^{\circ} \mathrm{W}\right)$ and (bottom) east $\left(75^{\circ} \mathrm{W}\right)$ longitudes. CONUS sector is indicated with dashed lines, including four (total) mesoscale boxes. Note the size of the pixel projected onto the Earth increases with view angle. Mesoscale box locations are movable to a target of interest. Colors represents the approximate pixel area of the nominal I-km bands. large increase in the number of detectors. For example, 16 detectors are downlinked for the current GOES imager, while the ABI will downlink almost 8,000 . This does not include the almost order of magnitude more redundant detectors on the $\mathrm{ABI}$. The $\mathrm{ABI}$ is designed to permit a wide range of image collection options. The baseline ground system supports the two required ABI scan modes. The first option is the scan mode 3 , also referred to as the "flex" mode timeline, consisting of FD scans every $15 \mathrm{~min}$, and continental U.S. (CONUS) images every $5 \mathrm{~min}$ and two mesoscale (nominally $1,000 \mathrm{~km}$ $\times 1,000 \mathrm{~km}$, at the subsatellite point) images every minute. The second mode, scan mode 4 , also referred to as the continuous full disk (CFD) timeline, consists of sequential FD scans every $5 \mathrm{~min}$.

Figure 5 demonstrates the coverage from the GOES-R operational locations $\left(137^{\circ}\right.$ and $75^{\circ} \mathrm{W}$ longitude). The size of the CONUS and mesoscale sectors is also shown. It should be noted that the CONUS sector has been shifted to the west, to include Hawaii, when viewed from the GOES-West position. The center points of the mesoscale sectors over the central United States are the same in the two panels. Mesoscale sectors will be selectable and these will be chosen based upon operational needs, such as tracking a hurricane, in anticipation of severe weather, or to cover wildfires and other potentially high-impact events. The mesoscale can also be used to collect vicarious calibration data. Figure 5 also shows in colored contours the relative size of the pixels, in this case 
for a 1-km-resolution band. For example, most of the CONUS from GOES-East should have approximately $2-\mathrm{km}$ spatial resolution for a band with a nadir resolution of $1 \mathrm{~km}$. During each of these modes, there are the needed space, blackbody, and star observations for radiometric calibration and navigation purposes.

Figures 6 and 7 show the "time-time" diagrams of what the ABI instrument does during each scan mode. The 15-min timeline of ABI scan mode 3 consists of 22 swaths to cover the FD,

three sets of 6 swaths to cover the CONUS 3 times, and 30 sets of two swaths to cover the mesoscale regions 30 times. White space in the diagram represents periods when the instrument is slewing the line-ofsight (LOS) from one observation to the next or waiting for the start of the next observation. During the scan mode 4 timeline, the FD is covered once with 22 swaths with the instrument actively scanning or making calibration measurements much of the time. This explains why the average data rate in the CFD mode is greater than that of the flex mode.

The operational flexibility of ABI permits the flex mode objectives to be improved upon with an FD every $10 \mathrm{~min}$. A possible future scan mode 6 timeline ("super flex") time-time diagram is shown in Fig. 8. Similar to the scan mode 3 timeline, CONUS is collected every $5 \mathrm{~min}$ and mesoscales are collected twice a minute. However, the FD is collected every $10 \mathrm{~min}$ instead of every $15 \mathrm{~min}$. This improved cadence would then match other advanced geostationary imagers, such as the AHI and the planned European Meteosat Third Generation Flexible Combined Imager. At the current time scan mode 6 is not supported by the operational ground system. However, it is a future capability available to NOAA that, when combined with other geostationary satellite imagers and computational enhancements, could greatly improve the temporal coverage outside of the CONUS domains. This would help in monitoring rapidly changing phenomena, such as volcanic ash clouds, and also for determining atmospheric motion vectors-the latter a key geostationary satellite product input into the global operational weather forecast models.

The ABI data will be remapped before distribution to the users. The data points in the GOES-R ABI Level $1 \mathrm{~b}$ products will be mapped to the "ABI fixed grid," which is a projection based on the viewing perspective of the idealized location of a satellite in geosynchronous orbit (Table 3). This is similar in operational concept to the European Organisation for the Exploitation of Meteorological Satellites (EUMETSAT)'s Spinning Enhanced Visible and Infrared Imager (SEVIRI) and GOES-10/-12 imager data used to support the Southern Hemisphere weather services (Schmetz et al. 2002; Schmit et al. 2009b). The ABI

\section{0 seconds}

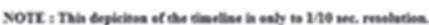

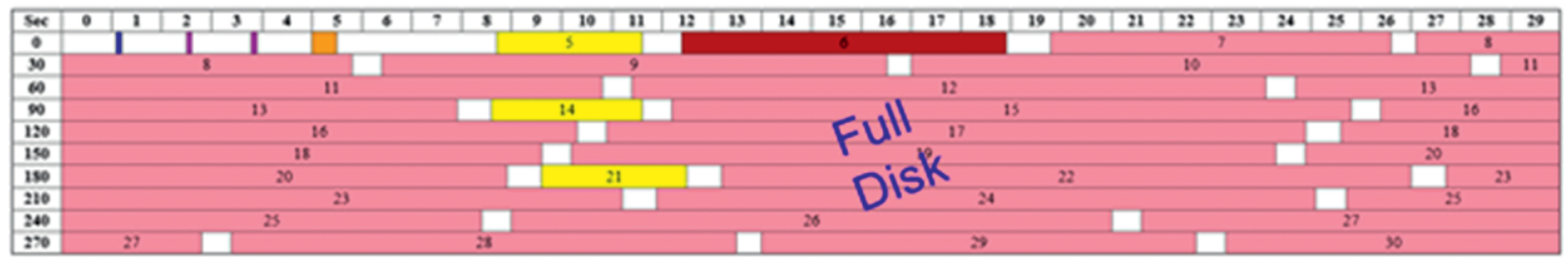

FIG. 7. ABI continuous FD (scan mode 4 timeline) time-time diagram. This timeline covers 5 min. 


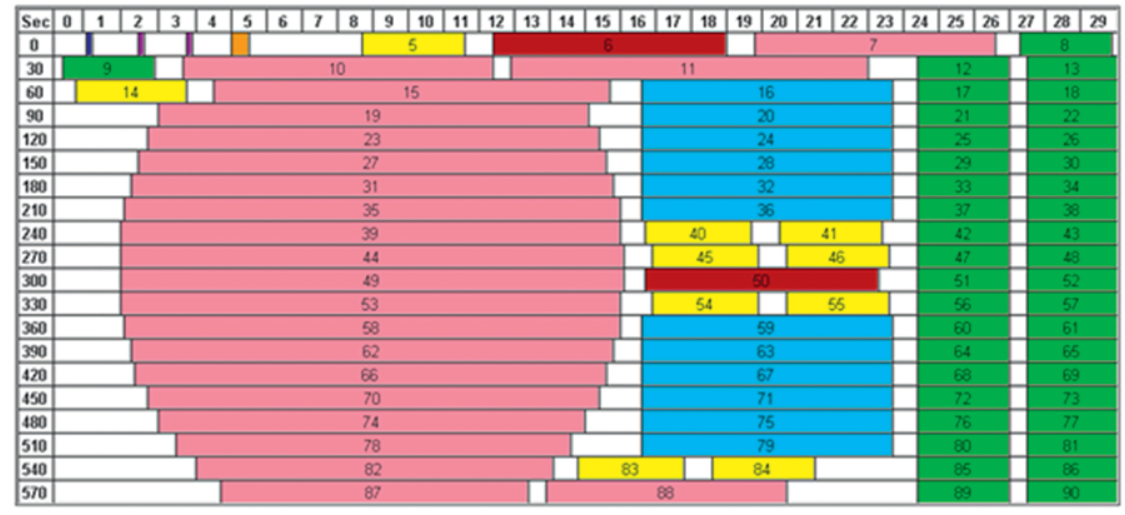

Fig. 8. ABI super flex (scan mode 6 timeline) time-time diagram (10-min FD, 5-min CONUS, 30-s mesoscale). This timeline covers 10 min. additional $\mathrm{ABI}$ bands will be fully utilized in the product algorithms that are used to produce this set of baseline environmental products. This is illustrated in Table 5, which indicates the ABI bands used to derive each of these products.

The derived products are retrieved via well-documented technical algorithms. Product algorithm details for all of the derived products are described in algorithm theoretical basis documents (ATBDs) that can be obtained from the official GOES-R website will remap to Earth locations, whereas previous geostationary imagers remapped the data for both Earth and space locations. Hence, previous imagers allow for viewing the atmosphere on the edge of Earth and part of space. This may be relevant when viewing the moon close to Earth, investigating any stray light from the sun, or viewing volcanoes or other special events of interest at the Earth's limb (Miller et al. 2013).

Figure 9 shows a simulated FD ABI scene, displayed in the Advanced Weather Interactive Processing System II (AWIPS II), that demonstrates end-to-end system testing conducted before launch. The complete suite of two visible bands, four nearIR bands, and 10 IR bands are shown. These images apply numerical weather prediction (NWP) forecast fields as input to advanced forward radiative transfer models that are capable of simulating these spectral bands (Otkin et al. 2009; Greenwald et al. 2016). These data have been continually generated in support of algorithm development in preparation for launch and operations. The simulations have been done for varying operational situations [scan modes and satellite positions, such as the ABI flex mode for the postlaunch check-out location $\left.\left(89.5^{\circ} \mathrm{W}\right)\right]$.

DERIVED PRODUCTS (LEVEL 2). In addition to imagery, these simulated data are being used to generate derived products as well. A number of baseline environmental Level 2 products will be produced from the ABI Level $1 \mathrm{~b}$ data. Table 4 lists these products and their associated attributes, which include geographic coverage, horizontal resolution, and product refresh rate. This information is from appendix A of NOAA-NASA (2016). All of the enhanced capabilities of the ABI described above will enable these improved product attributes to be realized. For example, the (www.goes-r.gov/). Further details on ABI-derived products can also be found in the literature (Bresky et al. 2012; Cintineo et al. 2013, 2014; Fang et al. 2014; Kalluri et al. 2015a; Lee et al. 2014; Pavolonis et al. 2013, 2015a,b; Schmit et al. 2015; Sieglaff et al. 2013, 2014). The tightly coupled product precedence chain is illustrated in Fig. 10, which shows both primary and secondary paths. For example, there are two options for the land surface temperature (LST) product to acquire snow cover information. The retrieval process for all of the derived products begins with the ABI Level $1 b$ (calibrated and navigated) data, with many of the Level 2 -derived products requiring the use of short-range forecasts from the National Weather Service's numerical weather prediction models together with clear-sky top-of-the-atmosphere (TOA) radiances computed via the Community Radiative Transfer Model (CRTM) (Ding et al. 2011) as initial conditions in the retrieval process. In addition to the images being obtained more rapidly from $A B I$, the data products will be generated more quickly as well.

Figure 11 is an example of two Level 2 products: color-coded total precipitable water and a grayscale of cloud-top temperature. The derived products will serve a large number of domestic and international users and will be used in a number of demanding real-time operational applications that include weather forecasting, numerical weather prediction, environmental monitoring, and other applications. This is where the real value of these derived products is realized. See the sidebar for some of the anticipated operational applications of the ABI-derived products in the operational application areas noted above.

A number of future capability Level 2 products enabled by the additional spectral channels of $\mathrm{ABI}$ 


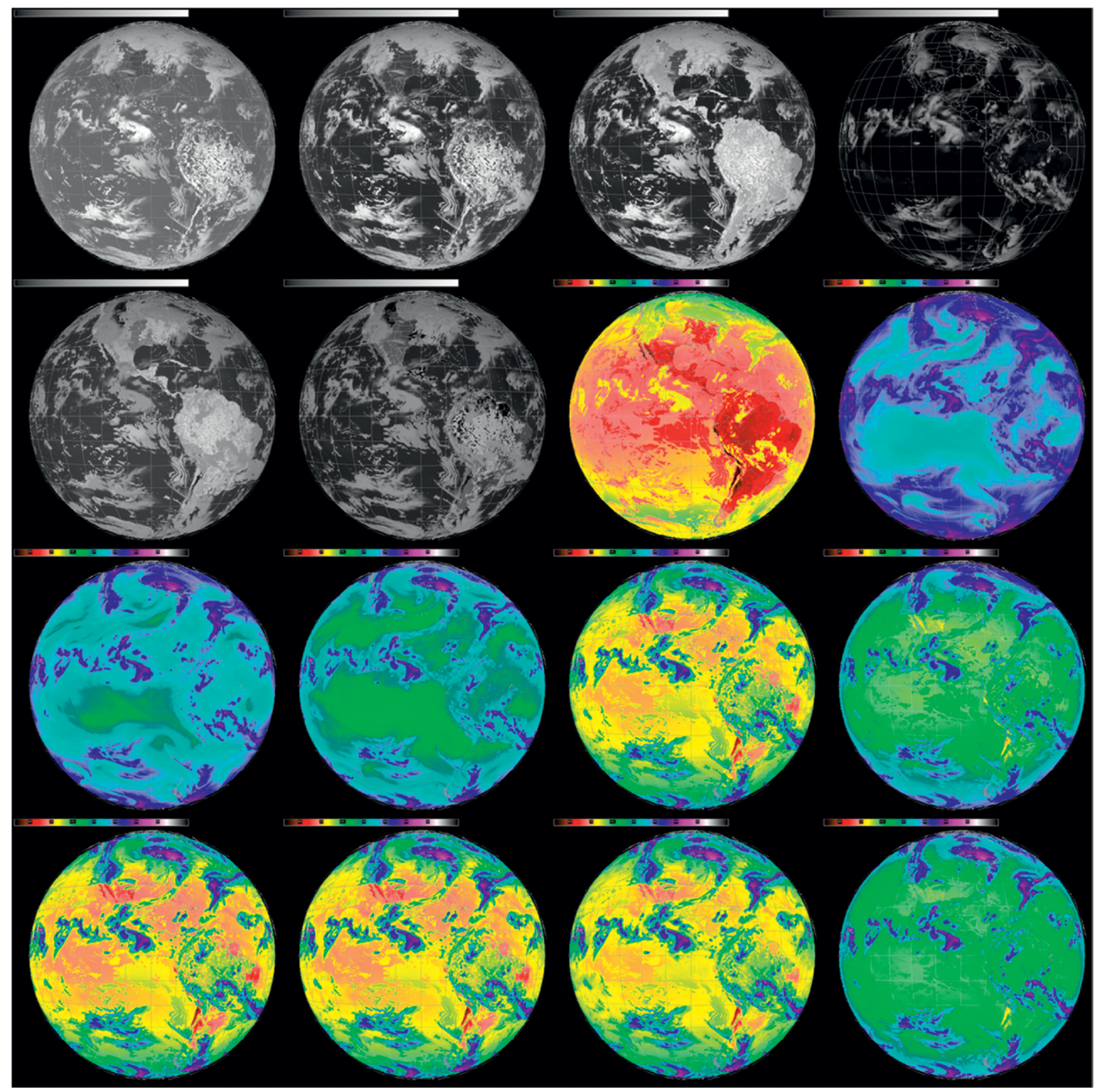

FIG. 9. ABI I6-band (simulated using NWP fields and an advanced forward model). These FD images were made in AWIPS II, using test data that were sent over the SBN. These data show the coverage from the central or test satellite subpoint.

have also been developed and the algorithms documented in ATBDs. These products include but are not limited to aircraft icing threat, cloud liquid water, cloud type, convective initiation, ice cover, low cloud and fog, total ozone, $\mathrm{SO}_{2}$ detection (associated with volcanic eruptions), surface emissivity, tropopause folding turbulence prediction, vegetation index, and visibility. More recently, there are a number of other derived product applications being developed and demonstrated for use in situational awareness or decision support situations. Examples of these product applications include red-green-blue (RGB) image composites, probabilistic forecasting of severe convection, and probabilistic forecasting of low clouds and fog. Many of these products are of high priority to the National Weather Service (NWS) and are expected to be implemented into forecast operations in the future.

PRODUCT AND DATA DELIVERY. There will be a number of data delivery pathways for the ABI imagery and data as with the other GOES-R instrument data products, including i) directly from the satellite (GRB-GOES-R rebroadcast), ii) via the 


\begin{tabular}{|c|c|c|c|}
\hline Baseline product & $\begin{array}{l}\text { Product geographic } \\
\text { coverage }\end{array}$ & $\begin{array}{l}\text { Product horizon- } \\
\text { tal resolution }\end{array}$ & $\begin{array}{l}\text { Refresh rate/coverage } \\
\text { time (mode } 3)\end{array}$ \\
\hline \multirow{3}{*}{$\begin{array}{l}\text { Aerosol detection (including } \\
\text { smoke and dust) }\end{array}$} & CONUS & \multirow{3}{*}{$2 \mathrm{~km}$} & CONUS: $15 \mathrm{~min}$ \\
\hline & FD & & FD: $15 \mathrm{~min}$ \\
\hline & Mesoscale & & Mesoscale: $15 \mathrm{~min}$ \\
\hline \multirow{2}{*}{ Aerosol optical depth } & CONUS & \multirow{2}{*}{$2 \mathrm{~km}$} & CONUS: $5 \mathrm{~min}$ \\
\hline & FD & & FD: $15 \mathrm{~min}$ \\
\hline Volcanic ash: Detection and height & FD & $2 \mathrm{~km}$ & FD: $15 \mathrm{~min}$ \\
\hline \multirow{3}{*}{ Cloud and moisture imagery } & CONUS & \multirow{3}{*}{$\begin{array}{l}2 \mathrm{~km} \text {, with finer day- } \\
\text { time observations }\end{array}$} & CONUS: $5 \mathrm{~min}$ \\
\hline & FD & & FD: $15 \mathrm{~min}$ \\
\hline & Mesoscale & & Mesoscale: $30 \mathrm{~s}$ \\
\hline \multirow{2}{*}{ Cloud optical depth } & CONUS: for optical depth $>$ I & CONUS: 2 km & CONUS: $15 \mathrm{~min}$ \\
\hline & FD: for optical depth > I & FD: $4 \mathrm{~km}$ & FD: $15 \mathrm{~min}$ \\
\hline \multirow{3}{*}{ Cloud particle size distribution } & CONUS & \multirow{3}{*}{$2 \mathrm{~km}$} & CONUS: $5 \mathrm{~min}$ \\
\hline & FD & & FD: $15 \mathrm{~min}$ \\
\hline & Mesoscale & & Mesoscale: $5 \mathrm{~min}$ \\
\hline \multirow{3}{*}{ Cloud-top phase } & CONUS & \multirow{3}{*}{$2 \mathrm{~km}$} & CONUS: $5 \mathrm{~min}$ \\
\hline & FD & & FD: $15 \mathrm{~min}$ \\
\hline & Mesoscale & & Mesoscale: $5 \mathrm{~min}$ \\
\hline \multirow{3}{*}{ Cloud-top height } & CONUS & CONUS: $10 \mathrm{~km}$ & CONUS: $60 \mathrm{~min}$ \\
\hline & FD & FD: $10 \mathrm{~km}$ & FD: $60 \mathrm{~min}$ \\
\hline & Mesoscale & Mesoscale: $4 \mathrm{~km}$ & Mesoscale: $5 \mathrm{~min}$ \\
\hline \multirow{2}{*}{ Cloud-top pressure } & CONUS & \multirow{2}{*}{$10 \mathrm{~km}$} & CONUS: $60 \mathrm{~min}$ \\
\hline & FD & & FD: $60 \mathrm{~min}$ \\
\hline \multirow{2}{*}{ Cloud-top temperature } & FD & \multirow{2}{*}{$2 \mathrm{~km}$} & FD: 15 min \\
\hline & Mesoscale & & Mesoscale: $5 \mathrm{~min}$ \\
\hline Hurricane intensity & FD & $2 \mathrm{~km}$ & FD: $30 \mathrm{~min}$ \\
\hline $\begin{array}{l}\text { Rainfall rate/quantitative precipita- } \\
\text { tion estimation (QPE) }\end{array}$ & FD & $2 \mathrm{~km}$ & FD: $15 \mathrm{~min}$ \\
\hline \multirow{3}{*}{ Legacy vertical moisture profile } & CONUS & \multirow{3}{*}{$10 \mathrm{~km}$} & CONUS: $30 \mathrm{~min}$ \\
\hline & FD & & FD: $60 \mathrm{~min}$ \\
\hline & Mesoscale & & Mesoscale: $5 \mathrm{~min}$ \\
\hline \multirow{3}{*}{$\begin{array}{l}\text { Legacy vertical temperature } \\
\text { profile }\end{array}$} & CONUS & \multirow{3}{*}{$10 \mathrm{~km}$} & CONUS: $30 \mathrm{~min}$ \\
\hline & FD & & FD: $60 \mathrm{~min}$ \\
\hline & Mesoscale & & Mesoscale: $5 \mathrm{~min}$ \\
\hline & CONUS & & CONUS: $30 \mathrm{~min}$ \\
\hline tive available potential energy & & 1 & FD: $60 \mathrm{~min}$ \\
\hline $\begin{array}{l}\text { (CAPE), lifted index, } K \text { index, } \\
\text { Showalter index, total totals] }\end{array}$ & Mesoscale & $10 \mathrm{~km}$ & Mesoscale: $5 \mathrm{~min}$ \\
\hline & CONUS & & CONUS: $30 \mathrm{~min}$ \\
\hline Total precipitable water & FD & $10 \mathrm{~km}$ & FD: $60 \mathrm{~min}$ \\
\hline & Mesoscale & & Mesoscale: 5 min \\
\hline & CONUS & & CONUS: $15 \mathrm{~min}$ \\
\hline Clear-sky masks & FD & $2 \mathrm{~km}$ & FD: $15 \mathrm{~min}$ \\
\hline & Mesoscale & & Mesoscale: $5 \mathrm{~min}$ \\
\hline & $\begin{array}{l}\text { CONUS: clear and above } \\
\text { cloud regions only }\end{array}$ & & CONUS: $15 \mathrm{~min}$ \\
\hline Radiances & $\begin{array}{l}\text { FD: clear and above cloud } \\
\text { regions only }\end{array}$ & $\begin{array}{l}\text { Individual channel } \\
\text { resolutions }(0.5,1.0 \text {, }\end{array}$ & FD: 15 min \\
\hline & $\begin{array}{l}\text { Mesoscale: clear and above } \\
\text { cloud regions only }\end{array}$ & & Mesoscale:5 min \\
\hline & CONUS & CONUS: 25 km & CONUS: $60 \mathrm{~min}$ \\
\hline Downward shortwave radiation: & FD & FD: $50 \mathrm{~km}$ & FD: $60 \mathrm{~min}$ \\
\hline & Mesoscale & Mesoscale: $5 \mathrm{~km}$ & Mesoscale: $60 \mathrm{~min}$ \\
\hline Reflected shortwave radiation: & CONUS & & CONUS: $60 \mathrm{~min}$ \\
\hline TOA & FD & & FD: $60 \mathrm{~min}$ \\
\hline & CONUS & & CONUS: $15 \mathrm{~min}$ \\
\hline & FD & & FD: 60 min (based on a \\
\hline Derived motion winds & & Band dependent & single set of three sequential \\
\hline & Mesoscale & & Images 5 min or more \\
\hline
\end{tabular}




\begin{tabular}{|c|c|c|c|}
\hline Baseline product & $\begin{array}{l}\text { Product geographic } \\
\text { coverage }\end{array}$ & $\begin{array}{l}\text { Product horizon- } \\
\text { tal resolution }\end{array}$ & $\begin{array}{c}\text { Refresh rate/coverage } \\
\text { time (mode } 3 \text { ) }\end{array}$ \\
\hline \multirow{2}{*}{ Fire/hotspot characterization } & CONUS & \multirow{2}{*}{$2 \mathrm{~km}$} & CONUS: $5 \mathrm{~min}$ \\
\hline & FD & & FD: 15 min \\
\hline \multirow{3}{*}{ Land surface (skin) temperature } & CONUS & CONUS: $2 \mathrm{~km}$ & CONUS: $60 \mathrm{~min}$ \\
\hline & FD & FD: $10 \mathrm{~km}$ & FD: $60 \mathrm{~min}$ \\
\hline & Mesoscale & Mesoscale: $2 \mathrm{~km}$ & Mesoscale: $60 \mathrm{~min}$ \\
\hline \multirow{3}{*}{ Snow cover } & CONUS & \multirow{3}{*}{$2 \mathrm{~km}$} & CONUS: $60 \mathrm{~min}$ \\
\hline & FD & & FD: $60 \mathrm{~min}$ \\
\hline & Mesoscale & & Mesoscale:60 min \\
\hline Sea surface temperature (skin) & FD & $2 \mathrm{~km}$ & FD: $60 \mathrm{~min}$ \\
\hline
\end{tabular}

Satellite Broadcast Network (SBN), and iii) terrestrial networks [product data access (PDA; Comprehensive Large Array-Data Stewardship System (CLASS)].

Those users with GOES-R GRB antennas will be able to ingest the GOES-R ABI data directly (Kalluri et al. 2015a). For those with a GRB feed, one option is the Community Satellite Processing Package for Geostationary (CSPP Geo) data for local processing (http://cimss.ssec.wisc.edu/csppgeo/). CSPP Geo is free to download and serves the direct broadcast community by providing the capability to generate geophysical products from geostationary satellite data.

The SBN, also known as NOAAPort, provides a one-way point to a multipoint broadcast of NOAA data in near-real time to NOAA and its private industry partners. Satellite imagery and derived products, GLM data, NWS radar, and numerical model grids together account for most of the data volume distributed via the SBN. The products selected for addition to the SBN product suite are primarily intended to meet the needs of users at NWS Weather Forecast Offices (WFOs), River Forecast Centers (RFCs), and national centers. It is also expected that NOAA's private industry partners will benefit from the network's product suite.

The NOAA National Environmental Satellite, Data, and Information Service (NESDIS) PDA system is the Environmental Satellite Processing and Distribution System (ESPDS) responsible for receiving and storing real-time environmental satellite data and products and for making them available to authorized users. The PDA will provide realtime distribution and access services for GOES-R users. GOES-R products will be served on PDA in Network Common Data Form 4 (netCDF4) format. Users will be able to utilize PDA tailoring capabilities for GOES-R data that include data sectorization, data remapping, and layer extraction. The previously mentioned ground system FPS also lists the latencies associated with the various products. CLASS is an electronic library of environmental data and is an online facility for the distribution of NOAA and U.S. Department of Defense (DoD) Polar-Orbiting Operational Environmental Satellite (POES) data, GOES data, and derived products.

SUMMARY. Ground tests have shown that the ABI will deliver high-quality images with significant margin against requirements in many areas of interest to the users, both domestic and international. This is also demonstrated with the high-quality images from the Japan Meteorological Agency (JMA)'s AHI instrument, which is very similar to the ABI. This ensures high-quality weather and environmental products, predictions, and accurate tracking of severe weather, such as hurricanes. Of course the ABI on the GOES-R series will not be used in isolation; the information will be combined with a number of other sensors,

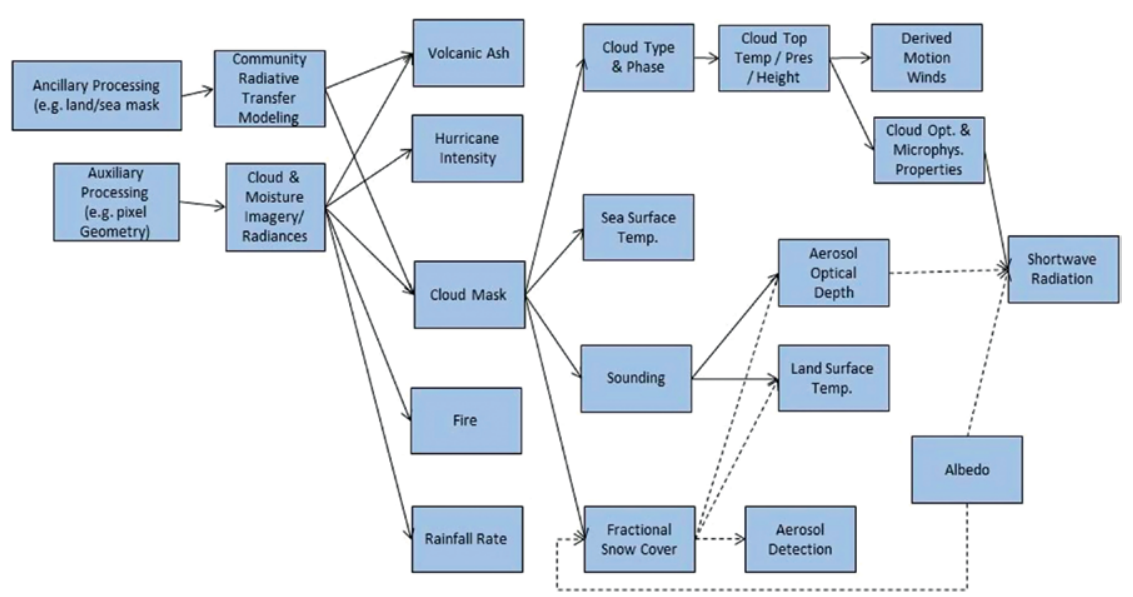

Fig. 10. End-to-end product precedence flow of ABI-derived products. The dashed lines represent secondary paths. 


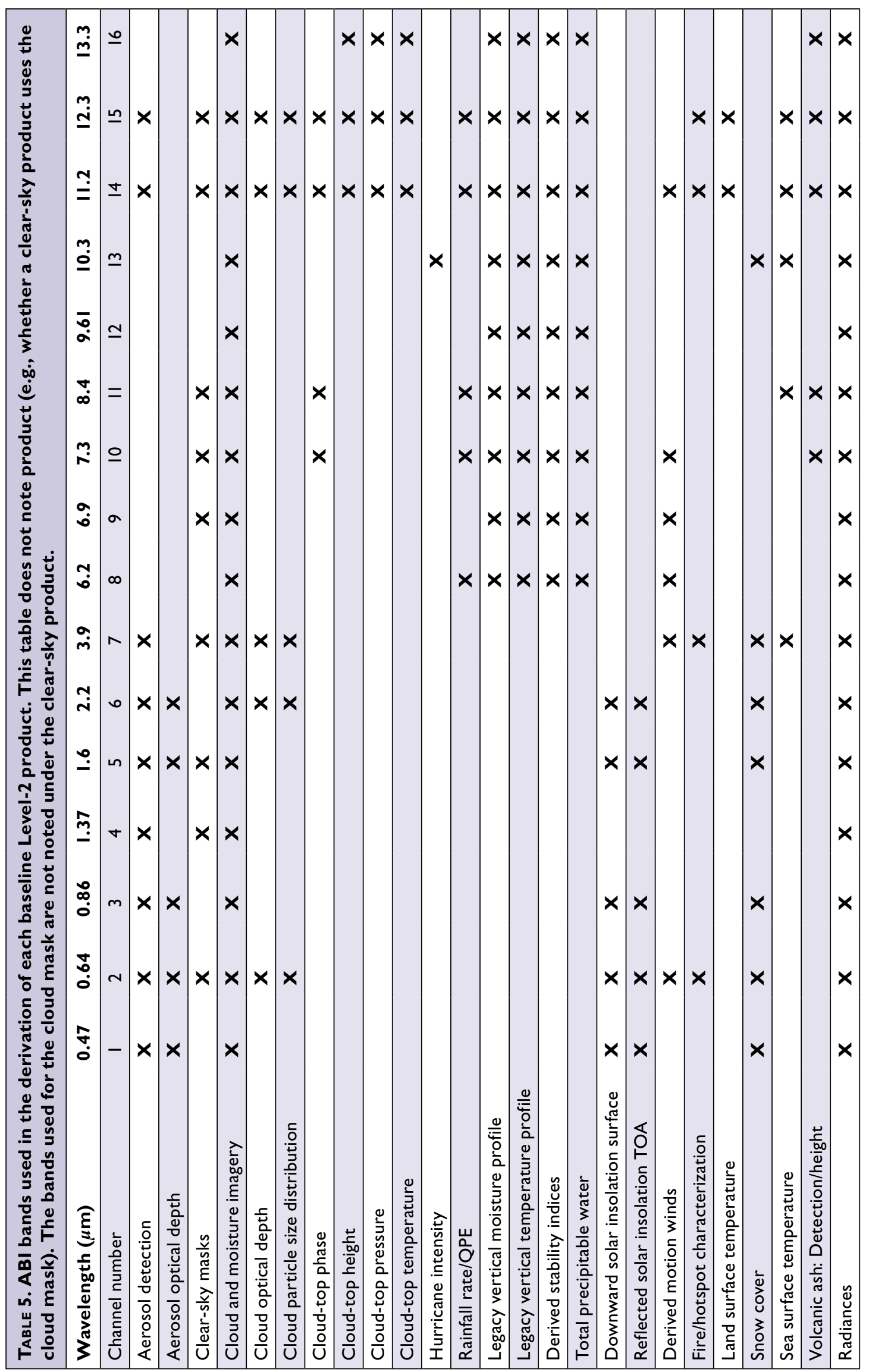


both space based (such as the GLM) and land based (such as radars). The GOES$\mathrm{R}$ ground system is being tested using high-quality simulated data. The GOESR Program website ( $w w w$ goes-r.gov) contains information on the launch schedule, along with information on the spacecraft, instruments, select imagery, user guides, products (including ATBDs for both baseline and future capabilities), and data access. In fact, there is a wide range of user training materials available, including $A B I$ band quick guides, distance-learning modules, short course material, and interactive web applications.

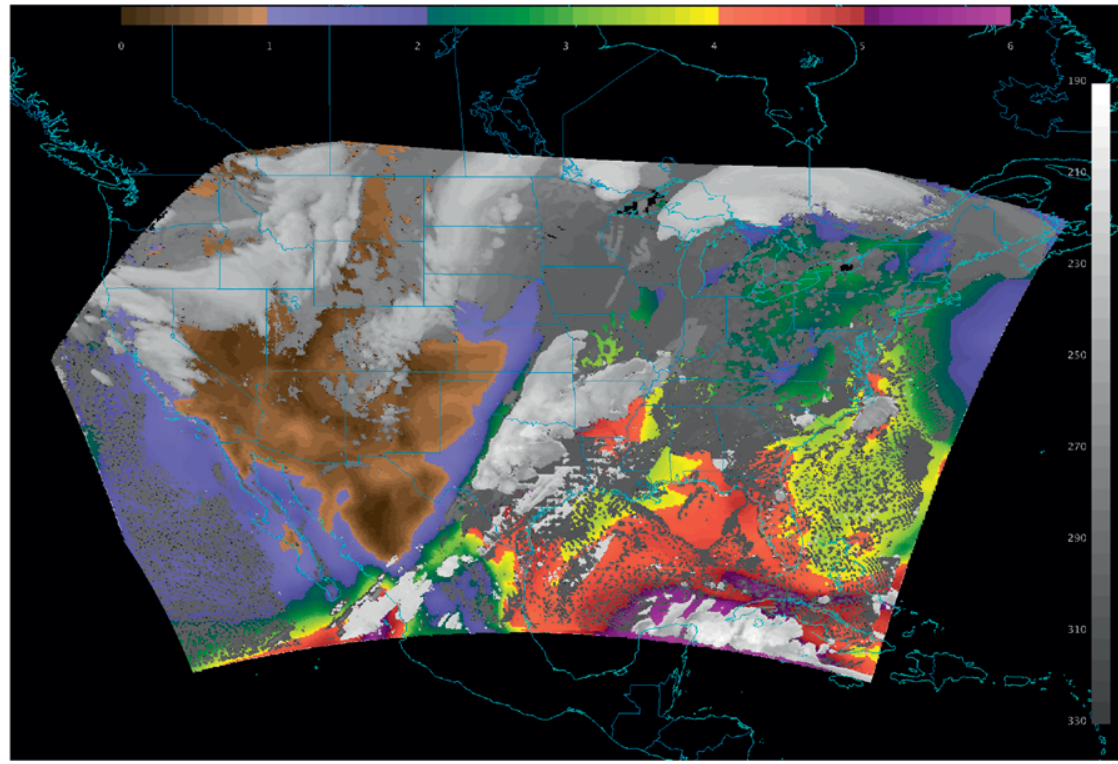

Fig. II. Two derived products (total precipitable water and cloud-top temperature) generated using simulated data from a Weather Research and Forecasting Model coupled with Chemistry (WRF-Chem) run. The valid time is 1600 UTC 5 Nov 2015.

There will be a number of data delivery methods for imagery and data from the ABI. These are directly from the satellite (GRB), via the SBN, and terrestrial networks (PDA and CLASS). In total, the daily data volume to CLASS for just one GOES-R satellite has been estimated to be $1 \mathrm{~TB}$ day $^{-1}$. In addition, there will be a number of web pages with imagery and/or derived products.

The ABI on the GOES-R series will dramatically improve the monitoring of many phenomena at finer time and space scales. The expected scan mode of the ABI will provide full disk imagery every $15 \mathrm{~min}$, CONUS imagery every $5 \mathrm{~min}$, and two mesoscale locations every minute. Many new spectral bands will be on the ABI that are not on the current GOES imager. Combined with information from the GLM, the ABI will provide an order-of-magnitude improvement for monitoring Earth's atmosphere, land, and oceans.

ACKNOWLEDGMENTS. The authors thank the many contributors to the development and generation of the ABI series on GOES-R. These include many in government, academia, and private industry. The groups include but are not limited to NOAA; NASA; the GOES-R Program Office (ground, program systems engineering, and flight); the NOAA/NESDIS cooperative institutes, such as CIMSS and CIRA; the Algorithm Working Group; the Product Working Group; the Calibration Working Group; the Product Readiness and Operations (PRO)

team; the color-table working group; and Harris Corporation, Lockheed Martin, and all the GOES-R instrument vendors. Kaba Bah of CIMSS is thanked for Fig. 11, while James P. Nelson III is thanked for the script for generating the animations in the supplemental material. Axel Graumann is acknowledged for the GOES-R data volume estimate. Don Hillger, Mike Weinreb, Kenneth Mitchell, and others are thanked for the current GOES imager noise values. Alan Reth is thanked for background information regarding the INR. The anonymous reviewers are thanked, especially reviewer 1 , as well as feedback from Yasuhiko Sumida of JMA. A combination of McIDAS-X and $-\mathrm{V}$ and MATLAB were used to make the figures. The views, opinions, and findings contained in this report are those of the authors and should not be construed as an official National Oceanic and Atmospheric Administration or U.S. government position, policy, or decision. More information about the GOES-14 SRSOR is available online (http://cimss.ssec.wisc.edu/goes /srsor/overview_training.html). This page includes the daily schedule, image center point, coverage area, and other information. More information on many of these cases can be found in the CIMSS Satellite Blog, under the GOES14 category (http://cimss.ssec.wisc.edu/goes/blog/archives /category/goes-14). Details on the GOES-R Education Proving Ground, including interactive web applications, can be found online (http://cimss.ssec.wisc.edu/education (goesr). This work was supported, in part, via NOAA Grant NA15NES4320001. 
REFERENCES

Albrecht, R. I., S. J. Goodman, D. E. Buechler, R. J. Blakeslee, and H. J. Christian, 2016: Where are the lightning hotspots on Earth? Bull. Amer. Meteor. Soc., 97, 2051-2068, doi:10.1175/BAMS-D-14-00193.1.

Apke, J. M., J. R. Mecikalski, and C. P. Jewett, 2016: Analysis of mesoscale atmospheric flows above mature deep convection using Super Rapid Scan geostationary satellite data. J. Appl. Meteor. Climatol., 55, 1859-1887, doi:10.1175/JAMC-D-15-0253.1.

Baucom, J. G., M. P. Weinreb, E. C. Wack, and R. X. Johnson, 1999: Post-launch tests of radiometric functions of GOES sensors. Earth Observing Systems IV, W. L. Barnes, Ed., International Society for Optical Engineering (SPIE Proceedings, Vol. 3750), 454, doi:10.1117/12.363541.

Bedka, K. M., J. Brunner, R. Dworak, W. Feltz, J. Otkin, and T. Greenwald, 2010: Objective satellite-based overshooting top detection using infrared window channel brightness temperature gradients. J. Appl. Meteor. Climatol., 49, 181-202, doi:10.1175/2009JAMC2286.1.

_ , C. Wang, R. Rogers, L. D. Carey, W. Feltz, and J. Kanak, 2015: Examining deep convective cloud evolution using total lightning, WSR-88D, and GOES-14 Super Rapid Scan datasets. Wea. Forecasting, 30, 571-590, doi:10.1175/WAF-D-14-00062.1.

Bessho, K., and Coauthors, 2016: An introduction to Himawari-8/9-Japan's new-generation geostationary meteorological satellites. J. Meteor. Soc. Japan, 94, 151-183, doi:10.2151/jmsj.2016-009.

Boeing, 2006: GOES N data book. Revision B, Boeing Co. Publ. CDRL PM-1-1-03, 220 pp. [Available online at http://goes.gsfc.nasa.gov/text/goes.databookn .html.]

Bresky, W. C., J. M. Daniels, A. A. Bailey, and S. T. Wanzong, 2012: New methods toward minimizing the slow speed bias associated with atmospheric motion vectors. J. Appl. Meteor. Climatol., 51, 2137-2151, doi:10.1175/JAMC-D-11-0234.1.

Bruning, E. C., and D. R. MacGorman, 2013: Theory and observations of controls on lightning flash spectra. J. Atmos. Soc., 70, 4012-4029, doi:10.1175 /JAS-D-12-0289.1.

Cecil, D. J., D. E. Buechler, and R. J. Blakeslee, 2014: Gridded lightning climatology from TRMM-LIS and OTD: Dataset description. Atmos. Res., 135-136, 404-414, doi:10.1016/j.atmosres.2012.06.028.

Christian, H. J., R. J. Blakeslee, and S. J. Goodman, 1989: The detection of lightning from geostationary orbit. J. Geophys. Res., 94, 13 329-13 337, doi:10.1029 /JD094iD11p13329.
Cintineo, J. L., M. J. Pavolonis, J. M. Sieglaff, and A. K. Heidinger, 2013: Evolution of severe and nonsevere convection inferred from GOES-derived cloud properties. J. Appl. Meteor. Climatol., 52, 2009-2023, doi:10.1175/JAMC-D-12-0330.1.

,,--- , and D. T. Lindsey, 2014: An empirical model for assessing the severe weather potential of developing convection. Wea. Forecasting, 29, 639-653, doi:10.1175/WAF-D-13-00113.1.

COESA, 1976: U.S. Standard Atmosphere, 1976. NOAA, $227 \mathrm{pp}$.

Da, C., 2015: Preliminary assessment of the Advanced Himawari Imager (AHI) measurement onboard Himawari-8 geostationary satellite. Remote Sens. Lett., 6, 637-646, doi:10.1080/2150704X.2015.1066522.

Daniels, J., W. Bresky, C. Velden, I. Genkova, S. Wanzong, and H. Berger, 2008: Algorithm and software development of atmospheric motion vector (AMV) products for the future GOES-R Advanced Baseline Imager. Proc. Ninth Int. Winds Workshop, Annapolis, MD, EUMETSAT. [Available online at http://cimss.ssec. wisc.edu/iwwg/workshop9/ext_abstracts/5.\%20 Daniels_Algorithm\%20adn\%20software\%20development\%20of\%20AMV\%20products\%20for\%20the $\% 20$ future\%20GOES-R\%20ABI.pdf.]

Davis G., 2007: History of the NOAA satellite program. J. Appl. Remote Sens., 1, 012504, doi:10.1117/1.2642347.

Ding, S., P. Yang, F. Weng, Q. Liu, Y. Han, P. van Delst, J. Li, and B. Baum, 2011: Validation of the Community Radiative Transfer Model. J. Quant. Spectrosc. Radiat. Transfer, 112, 1050-1064, doi:10.1016/j.jqsrt.2010.11.009.

Dworak, R., K. Bedka, J. Brunner, and W. Feltz, 2012: Comparison between GOES-12 overshooting-top detections, WSR-88D radar reflectivity, and severe storm reports. Wea. Forecasting, 27, 684-699, doi:10.1175/WAF-D-11-00070.1.

Fang, L., Y. Yu, H. Xu, and D. Sun, 2014: New retrieval algorithm for deriving land surface temperature from geostationary orbiting satellite observations. IEEE Trans. Geosci. Remote Sens., 52, 819-828, doi:10.1109/TGRS.2013.2244213.

Gatlin, P. N., and S. J. Goodman, 2010: A total lightning trending algorithm to identify severe thunderstorms. J. Atmos. Oceanic Technol., 27, 3-22, doi:10.1175/2009JTECHA1286.1.

Goodman, S. J., and Coauthors, 2012: The GOES-R Proving Ground: Accelerating user readiness for the next-generation geostationary environmental satellite system. Bull. Amer. Meteor. Soc., 93, 1029-1040, doi:10.1175/BAMS-D-11-00175.1.

- and Coauthors, 2013: The GOES-R Geostationary Lightning Mapper (GLM). Atmos. Res., 125-126, 34-49, doi:10.1016/j.atmosres.2013.01.006. 
Gravelle, C. M., J. R. Mecikalski, W. E. Line, K. M. Bedka, R. A. Petersen, J. M. Sieglaff, G. T. Stano, and S. J. Goodman, 2016: Demonstration of a GOES-R satellite convective toolkit to "bridge the gap" between severe weather watches and warnings: An example from the 20 May 2013 Moore, Oklahoma, tornado outbreak. Bull. Amer. Meteor. Soc., 97, 69-84, doi:10.1175/BAMS-D-14-00054.1.

Greenwald, T., and Coauthors, 2016: Real-time simulation of the GOES-R ABI for user readiness and product evaluation. Bull. Amer. Meteor. Soc., 97, 245-261, doi:10.1175/BAMS-D-14-00007.1.

Hayden, C. M., and T. J. Schmit, 1991: The anticipated sounding capabilities of GOES-I and beyond. Bull. Amer. Meteor. Soc., 72, 1835-1846, doi:10.1175/1520 -0477(1991)072<1835:TASCOG>2.0.CO;2.

Hillger, D. W., and T. J. Schmit, 2011: The GOES-15 science test: Imager and sounder radiance and product validations. NOAA Tech. Rep. NESDIS 141, 101 pp.

,-- , and J. M. Daniels, 2003: Imager and sounder radiance and product validation for the GOES-12 science test. NOAA Tech. Rep. NESDIS 115, 66 pp.

Kalluri, S., J. Gundy, B. Haman, A. Paullin, P. Van Rompay, D. Vititoe, and A. Weiner, 2015a: A high performance remote sensing product generation system based on a service oriented architecture for the next generation of Geostationary Operational Environmental Satellites. Remote Sens., 7, 10385-10399, doi:10.3390/rs70810385.

— , P. Sullivan, and S. Goodman, 2015b: The next series of geostationary weather satellites. Meteor. Technol. Int., April, 16-20.

Lee, Y., Z. Li, J. Li, and T. J. Schmit, 2014: Evaluation of the GOES-R ABI LAP retrieval algorithm using the GOES-13 sounder. J. Atmos. Oceanic Technol., 31, 3-19, doi:10.1175/JTECH-D-13-00028.1.

Lindsey, D. T., T. J. Schmit, W. M. MacKenzie Jr., C. P. Jewett, M. M. Gunshor, and L. Grasso, 2012: 10.35 $\mu \mathrm{m}$ : An atmospheric window on the GOES-R Advanced Baseline Imager with less moisture attenuation. J. Appl. Remote Sens., 6, 063598, doi:10.1117/1 .JRS.6.063598.

Line, W., T. J. Schmit, D. T. Lindsey, and S. J. Goodman, 2016: Use of geostationary rapid scan imagery by the Storm Prediction Center (SPC). Wea. Forecasting, 31, 483-494, doi:10.1175/WAF-D-15-0135.1.

Mecikalski, J. R., C. P. Jewett, J. M. Apke, and L. D. Carey, 2016: Analysis of cumulus cloud updrafts as observed with 1-min resolution Super Rapid Scan GOES imagery. Mon. Wea. Rev., 144, 811-830, doi:10.1175/MWR-D-14-00399.1.

Menzel, W. P., and J. F. W. Purdom, 1994: Introducing GOES-I: The first of a new generation of
Geostationary Operational Environmental Satellites. Bull. Amer. Meteor. Soc., 75, 757-781, doi:10.1175/1520 -0477(1994)075<0757:IGITFO>2.0.CO;2.

Miller, S. D., C. C. Schmidt, T. J. Schmit, and D. W. Hillger, 2012: A case for natural colour imagery from geostationary satellites, and an approximation for the GOESR ABI. Int. J. Remote Sens., 33, 3999-4028, doi:10 .1080/01431161.2011.637529.

— W. W. Straka III, A. S. Bachmeier, T. J. Schmit, P. T. Partain, and Y.-J. Noh, 2013: Earth-viewing satellite perspectives on the Chelyabinsk meteor event. Proc. Natl. Acad. Sci. USA, 110, $18092-18097$, doi:10.1073 /pnas.1307965110.

—, T. J. Schmit, C. Seaman, D. T. Lindsey, M. M. Gunshor, R. A. Kohrs, Y. Sumida, and D Hillger, 2016: A sight for sore eyes-The return of true color to geostationary satellites. Bull. Amer. Meteor. Soc., 97, 1803-1816, doi:10.1175/BAMS-D-15-00154.1.

NOAA, 2015a: Mesoscale discussion 721. [Available online at www.spc.noaa.gov/products/md/2015 /md0721.html.]

_, $2015 \mathrm{~b}$ : Mesoscale discussion 722. [Available online at www.spc.noaa.gov/products/md/2015/md0722 .html.]

NOAA-NASA, 2016: GOES-R series: Ground segment project. Version 3.9, Functional and Performance Specification 416-R-FPS-0089, 298 pp. [Available online at www.goes-r.gov/resources/docs/GOES -R_GS_FPS.pdf.]

Okuyama, A., and Coauthors, 2015: Preliminary validation of Himawari-8/AHI navigation and calibration. Earth Observing Systems XX, J. J. Butler, X. Xiong, and $\mathrm{X}$. Gu, Eds., International Society for Optical Engineering (SPIE Proceedings, Vol. 9607), 96072E, doi:10.1117/12.2188978.

Otkin, J. A., T. J. Greenwald, J. Sieglaff, and H. L. Huang, 2009: Validation of a large-scale simulated brightness temperature dataset using SEVIRI satellite observations. J. Appl. Meteor. Climatol., 48, 1613-1626, doi:10.1175/2009JAMC2142.1.

Pavolonis, M. J., A. K. Heidinger, and J. Sieglaff, 2013: Automated retrievals of volcanic ash and dust cloud properties from upwelling infrared measurements. J. Geophys. Res. Atmos., 118, 1436-1458, doi:10.1002 /jgrd.50173.

— , J. Sieglaff, and J. Cintineo, 2015a: Spectrally enhanced cloud objects-A generalized framework for automated detection of volcanic ash and dust clouds using passive satellite measurements: 1 . Multispectral analysis. J. Geophys. Res. Atmos., 120, 7813-7841, doi:10.1002/2014JD022968.

$\longrightarrow, \ldots$, and —_, 2015b: Spectrally enhanced cloud objects-A generalized framework for automated 
detection of volcanic ash and dust clouds using passive satellite measurements: 2 . Cloud object analysis and global application. J. Geophys. Res. Atmos., 120, 7842-7870, doi:10.1002/2014JD022969.

Petersen, W. A., H. J. Christian, and S. A. Rutledge, 2005: TRMM observations of the global relationship between ice water content and lightning. Geophys. Res. Lett., 32, L14819, doi:10.1029/2005GL023236.

Ralph, R. M., and Coauthors, 2013: The emergence of weather-related test beds linking research and forecasting operations. Bull. Amer. Meteor. Soc., 94, 1187-1211, doi:10.1175/BAMS-D-12-00080.1.

Schmetz, J., P. Pili, S. Tjemkes, D. Just, J. Kerkmann, S. Rota, and A. Ratier, 2002: An introduction to Meteosat Second Generation (MSG). Bull. Amer. Meteor. Soc., 83, 977-992, doi:10.1175/1520 -0477(2002)083<0977:AITMSG>2.3.CO;2.

Schmit, T. J., W. F. Feltz, W. P. Menzel, J. Jung, A. P. Noel, J. N. Heil, J. P. Nelson III, and G. S. Wade, 2002: Validation and use of GOES sounder moisture information. Wea. Forecasting, 17, 139-154, doi:10.1175/1520 -0434(2002)017<0139:VAUOGS>2.0.CO;2.

—, M. M. Gunshor, W. P. Menzel, J. J. Gurka, J. Li, and A. S. Bachmeier, 2005: Introducing the nextgeneration Advanced Baseline Imager (ABI) on GOES-R. Bull. Amer. Meteor. Soc., 86, 1079-1096, doi:10.1175/BAMS-86-8-1079.

—, J. Li, J. N. Li, W. F. Feltz, J. J. Gurka, M. D. Goldberg, and K. J. Schrab, 2008: The GOES-R Advanced Baseline Imager and the continuation of current sounder products. J. Appl. Meteor. Climatol., 47, 2696-2711, doi:10.1175/2008JAMC1858.1.

,-- , S. A. Ackerman, and J. J. Gurka, 2009a: High-spectral- and high-temporal-resolution infrared measurements from geostationary orbit. $J$. Atmos. Oceanic Technol., 26, 2273-2292, doi:10.1175 /2009JTECHA1248.1.

— , and Coauthors, 2009b: Many uses of the Geostationary Operational Environmental Satellite-10 sounder and imager during a high inclination state. J. Appl. Remote Sens., 3, 033514, doi:10.1117/1.3099709.

—_ and Coauthors, 2013: Geostationary Operational Environmental Satellite (GOES)-14 super rapid scan operations to prepare for GOES-R. J. Appl. Remote Sens., 7, 073462, doi:10.1117/1.JRS.7.073462.
— of significant events: Preparing users for the next generation of geostationary operational satellites. Bull. Amer. Meteor. Soc., 96, 561-576, doi:10.1175 /BAMS-D-13-00210.1.

Schultz, C. J., W. A. Petersen, and L. D. Carey, 2009: Preliminary development and evaluation of lightning jump algorithms for the real-time detection of severe weather. J. Appl. Meteor. Climatol., 48, 2543-2563, doi:10.1175/2009JAMC2237.1.

,-- , and — 2011: Lightning and severe weather: A comparison between total and cloud-to-ground lightning trends. Wea. Forecasting, 26, 744-755, doi:10.1175/WAF-D-10-05026.1.

Sieglaff, J. M., D. C. Hartung, W. F. Feltz, L. M. Cronce, and L. Valliappa, 2013: A satellite-based convective cloud object tracking and multipurpose data fusion tool with application to developing convection. $J$. Atmos. Oceanic Technol., 30, 510-525, doi:10.1175 /JTECH-D-12-00114.1.

—, L. M. Cronce, and W. F. Feltz, 2014: Improving satellite-based convective cloud growth monitoring with visible optical depth retrievals. J. Appl. Meteor. Climatol., 53, 506-520, doi:10.1175/JAMC-D-13-0139.1.

Stano, G. T., C. J. Schultz, L. D. Carey, D. R. MacGorman, and K. M. Calhoun, 2014: Total lightning observations and tools for the 20 May 2013 Moore, Oklahoma, tornadic supercell. J. Oper. Meteor., 2, 71-88, doi:10.15191/nwajom.2014.0207.

Suomi, V. E., and R. Parent, 1968: A color view of Planet Earth. Bull. Amer. Meteor. Soc., 49, 74-75.

Xiong, X., H. Erives, S. Xiong, X. Xie, J. Esposito, J. Sun, and W. Barnes, 2005: Performance of Terra MODIS solar diffuser and solar diffuser stability monitor. Observing Systems X, J. J. Butler, Ed., International Society for Optical Engineering (SPIE Proceedings, Vol. 5882), 58820S, doi:10.1117/12.615334.

Zipser, E. J., and K. R. Lutz, 1994: The vertical profile of radar reflectivity of convective cells: A strong indicator of storm intensity and lightning probability? Mon. Wea. Rev., 122, 1751-1759, doi:10.1175/1520 -0493(1994)122<1751:TVPORR>2.0.CO;2.

—, C. Liu, D. J. Cecil, S. W. Nesbitt, and D. P. Yorty, 2006: Where are the most intense thunderstorms on Earth? Bull. Amer. Meteor. Soc., 87, 1057-1071, doi:10.1175/BAMS-87-8-1057. 